\title{
THE INFLUENCE OF PROBIOTIC LACTOBACILLI AND FLAXSEED ON THE HEALTH OF WEANED PIGLETS AND METABOLISM OF POLYUNSATURATED FATTY ACIDS (PUFAs)
}

\author{
Sopková, D. ${ }^{1}$, Vlčková, R. ${ }^{1}$, Andrejčáková, Z. ${ }^{1}$ \\ Hertelyová, Z. ${ }^{2}$, Gancarč́ková, S. ${ }^{1}$, Nemcová, R. ${ }^{1}$ \\ ${ }^{1}$ University of Veterinary Medicine and Pharmacy, Komenského 73, 04181 Košice \\ ${ }^{2}$ Faculty of Medicine, University of Pavol Jozef Šafarik, SNP 1, 04066 Košice \\ The Slovak Republic \\ drahomira.sopkova@uvlf.sk
}

\begin{abstract}
This study investigated for 14 days post-weaning, the influence of dietary supplementation of synbiotics in the form of probiotic cheeses containing cultures of L. plantarum and L.fermentum and crushed flaxseed (source of $\omega-3$ polyunsaturated fatty acids - PUFAs and fibre) on 36 commercial piglets originating from an infected herd (Coronavirus and E. coli) during the critical period of weaning. We focused on the health and metabolism of PUFAs in this critical period of a piglet's life. The dietary supplementation positively affected: the overall health state of weaners, reduced diarrhoea by $29 \%$ by 14 days post-weaning and significantly increased the counts of lactic acid bacteria, bifidobacteria and the production of volatile fatty acids. The PUFA concentrations in the $m$. biceps femoris of the piglets were analysed by gas chromatography. High levels of $\omega$-3 alpha-linolenic acid (ALA) in flaxseed increased significantly the level of ALA, eicosapentaenic acid (EPA) and docosahexaenic acid (DHA) in the pig muscles on days 7 and 14 postweaning. The levels of $\omega-6$ linolenic acid (LA) were less
\end{abstract}

affected by the diet, but were increased on day 14 postweaning, while the conversion products of LA, and arachidonic acid (AA), were decreased on days 7 and 14 . The increased level of dietary ALA favoured the activity of $\Delta$-6-desaturase for the conversion of ALA to EPA and DHA, at the expense of AA synthesis from LA. The ability of synbiotics to incorporate high levels of DHA in the pig muscles appear prospective for improving the nutritional properties of pork and reducing the occurrence of civilization diseases in consumers of this product of animal origin.

Key words: flaxseed; health; polyunsaturated fatty acids (PUFAs); probiotics; weaned piglet

\section{INTRODUCTION}

Weaning of piglets is associated with abrupt dietary changes resulting in morphological and functional changes in their intestinal ecosystem. This is one of the reasons why weaners are particularly susceptible for developing 
digestive diseases $[33,37]$. Biological barriers in the digestive system provide basic primary protection to organisms against negative influences and here probiotics offer a prospective alternative to antibiotics. The effect of probiotics can be supported by prebiotics (potentiated probiotics, also referred to as synbiotics) [4]. These natural bioregulators participate in: the maintenance of the balance of intestinal microflora, prevent colonisation of pathogenic microorganisms [5], optimise digestive processes [9] and, at the same time, stimulate the immune system [19].

Flaxseed can be used as a prebiotic substrate of natural origin. Flaxseed hulls contain soluble viscous polysaccharides which serve as a specific substrate for probiotic bacteria [35]. Flaxseed is also a rich source of polyunsaturated fatty acids (PUFAs), the structural components of cell membranes. Changes in the composition of fatty acids (FAs) in cellular membranes and intestinal mucosa may affect the mechanisms and adherence sites of intestinal bacteria and, subsequently, cause changes in populations of the bacteria in the intestine [33]. Through such mechanisms, the dietary PUFAs may positively affect the health of weaners and support their rapid adjustment to the character of post-weaning diet [21]. The high content of essential $\omega-3$ alpha-linolenic acid (ALA) in flaxseed may positively affect the serum levels of lipoproteins and triacylglycerols [31] and affect the animal products nutritionally by additional $\omega$-3 PUFAs produced at biosynthesis in animal tissues [18].

Food research is a field very much oriented on the search for terrestrial sources of $\omega-3$ PUFAs which could supplement human diet deficient in this type of fatty acids. Animal products could be used as a suitable source, particularly of long-chain fatty acids synthesised in the body of mammals, such as eicosapentaenoic acid (EPA) and docosahexaenoic acid (DHA). High proportion (50-61 \%) of essential $\omega-3$ ALA in flaxseed oil can therefore be used very effectively to increase the content of $\omega$-3 PUFAs in animal products, particularly those of monogastric animals in which the FAs taken up in feed are absorbed in the small intestine in an unchanged form and are subsequently incorporated into tissues. Contrary to ruminants, in monogastric animals FAs are not subjected to biohydrogenation before they enter the small intestine. In the process of biohydrogenation in ruminants, which takes place under the action of micro-organisms in the rumen, FAs present in the feed are converted to unsaturated and saturated ones. For this reason, only smaller proportion of dietary PUFAs are incorporated in phospholipids and triacylglycerols of body tissues $[18,40]$. In pigs, there is a close correlation between the amount of FAs in the diet and their tissues and the FA profile may be then easier affected by the diet [40]. Under our conditions, flaxseed appears to be a very suitable option for increasing the content of $\omega-3$ PUFAs in animal tissues and subsequently in animal products, particularly due to the high content of essential ALA in flaxseed, the precursor of EPA and DHA synthesis in animal bodies.

With regard to the ever increasing occurrence of "civilization diseases", development of resistance to antibiotics and increasing interest of the public in using ecological methods in food industry, agriculture and medicine in the field of prevention and treatment of diseases, researchers should focus their attention on suitable biologically active additives of natural origin that are beneficial to health and do not present risk to the food chain.

For the above reasons, the aim of our study was to investigate the influence of feed supplementation with synbiotics, probiotic cheeses containing cultures of $L$. plantarum and L. fermentum and crushed flaxseed (source of $\omega-3$ PUFAs and fibre), to commercial piglets originating from infected herd during the critical post-weaning period with a focus on their health and metabolism of PUFAs.

\section{MATERIALS AND METHODS}

\section{Animals and diets}

This study was carried out on thirty-six 28-day old piglets of Slovak white $\times$ Landrace cross-breed, originating from a herd (KOAN s.r.o., Krásnovce, Slovak Republic) where the Coronavirus and enterotoxigenic E. coli (ETEC) infections were confirmed. The piglets were transported to the experimental housing facility at the Institute of Microbiology and Gnotobiology, University of Veterinary Medicine and Pharmacy (UVMP) in Košice, the Slovak Republic, where the dietary supplementation experiments were performed. The experimental design is illustrated in Fig. 1. The experiments were approved by the State Veterinary and Food Administration of the Slovak Republic (Approval No. 2519/10-221). The animals were handled in accordance with the guidelines established by the relevant commission. They were housed at an ambient temperature of $20-22^{\circ} \mathrm{C}$ in stainless steel cages where $1 / 4$ of the floor was slotted and $3 / 4$ were covered with an insulating rubber layer. 
The animals were divided into two groups: control (C; $\mathrm{n}=18$, control cheese) and experimental group (LFA; $\mathrm{n}=18$, probiotic cheeses with addition of Lactobacilli + crushed flax-seed as a source of PUFAs). Throughout the study, the animals were fed commercial mixed feed for early weaned piglets OŠ-02 (Spišské Vlachy, SR) and had ad libitum access to water. The mixed feed was supplemented (LFA group) with crushed flax-seed (cultivar Flanders, Agritec, Czech Republic) at a concentration of $10 \%$ (continuously added to rations). In the period starting 10 days before weaning and lasting up to 14 days post-weaning, the piglets in the LFA group were supplied probiotic cheeses ( $4 \mathrm{~g}$ per head per day of each cheese), and crushed flax-seed. Piglets in the $C$ group were supplied control cheese $(8 \mathrm{~g} /$ per head per day). Both types of cheeses were sprinkled on the surface of the feed.

Cheddar cheese chemical composition: proteins $23.8 \%$, sugars $2.8 \%$, lipids $30.1 \%$, and metabolisable energy $1.62 \mathrm{MJ} . \mathrm{kg}^{-1}$. This cheese was used as a vehicle for probiotic strains. Each of two cheeses contained one strain at $1 \times 10^{9} \mathrm{CFU}^{-1} \mathrm{~g}^{-1}$ of cheese (referred to as probiotic cheeses). The probiotic bacteria were added to the cheese milk together with $2 \%$ starter culture (Lactococcus lactis subsp. lactis, Lactococcus lactis subsp. cremoris) during the typical Cheddar cheese production.

The cheese used as the control was also Cheddar cheese, but without probiotic strains (referred to as control cheese).

\section{Probiotic bacteria}

The Lactobacillus probiotic strains were isolated in the laboratory of the Institute of Microbiology and Gnotobiology, UVMP in Košice, the Slovak Republic. The Lactobacillus plantarum Biocenol ${ }^{\mathrm{TN}}$ LP96 (CCM 7512) strain was isolated from the gut of healthy suckling piglets. This strain was characterized by: strong adherence to the epithelial cells of porcine intestine; inhibitory activity against Escherichia coli O8:K88ab:H9 under in vitro conditions; and production of hydrogen peroxide [23]. The Lactobacillus fermentum Biocenol $^{\text {TM }}$ LF99 (CCM 7514) was isolated from the gastrointestinal tract of adult chickens. The strain was characterized by: growth in the presence of bile acids and gastric juice; sensitivity to antibiotics; inhibitory activity against Salmonella enterica serovar Enteritidis and Salmonella enterica serovar Düsseldorf [24].

\section{Clinical observations and muscle sampling}

During the experimental period, all piglets underwent clinical observations. The health data were recorded twice daily (at 08.00 a.m. and 03.00 p.m.), namely: body temperature, consistency of faeces and moisture of faeces. Samples of faeces were assessed visually using a scale from 1 to 5 ( 1 - solid faeces; 2 - paste; 3 - sparse; 4 - hydrous; 5 - faeces with blood or mucus admixture). The moisture of faeces was determined by drying a sample of faeces at $80^{\circ} \mathrm{C}$ to a constant weight.

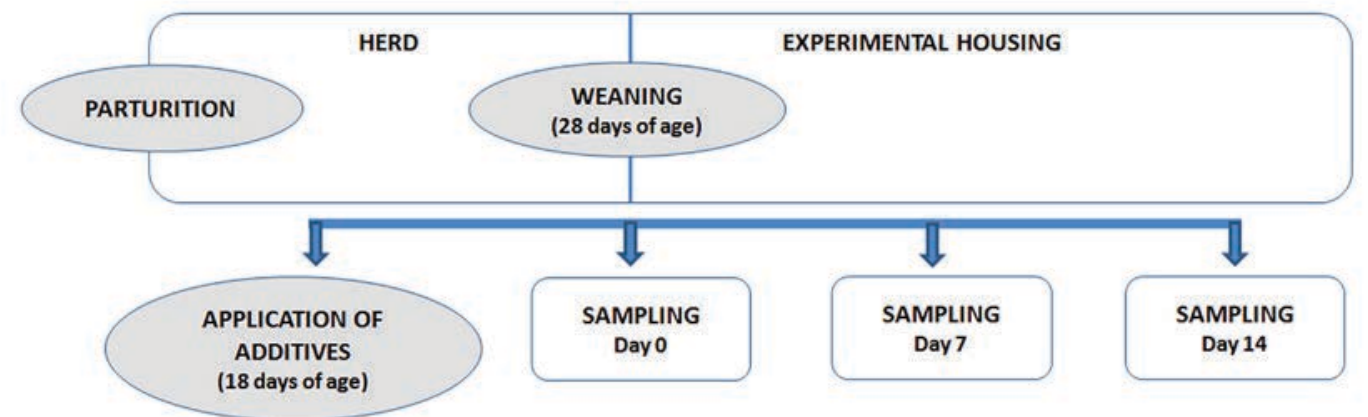

Fig. 1. Schematic representation of experimental design

Note: Day 0 is the day of piglet weaning, days 7 and 14 are the days of supplementation of the rations after weaning. Supplementation to experimental animals started 10 days before weaning (at 18 days of the piglets' age) and lasted up to 14 days after weaning. The muscle samples were collected from the $\mathrm{m}$. biceps femoris of piglets after feeding with or without synbiotic additives on these days. 
Piglets from both groups were humanely euthanized by intracardiac administration of T61 a.u.v. (Intervet International B.V. Boxmeer, the Netherlands) at a dose of $1 \mathrm{ml}$. $\mathrm{kg}^{-1} \cdot$ head $^{-1}$ on days 0 (day of weaning; $\mathrm{n}=6$ ), $7(\mathrm{n}=6)$ and $14(n=6)$ post-weaning and skeletal muscle samples for the analysis of PUFAs were taken from the musculus biceps femoris (sample $=2$ g; see Fig. 1). All samples were stored at $-70^{\circ} \mathrm{C}$ until analysis.

\section{Gas chromatography}

The extraction of fatty acids was performed by modification of the method of Folch [8] using dichloromethane instead of chloroform [6] according to Tvrzická et al. [34]. A Clarity Chromatography Station data integration system was used to integrate the peak areas. The FA concentration (c) in pig serum was calculated as follows:

$c\left(\mathrm{mg}^{-1}\right)=\frac{\text { peak area of a given FA } \times c \text { of internal standard }\left(\mathrm{mg} \cdot \mathrm{ml}^{-1}\right)}{\text { peak area of internal standard or sample }(\mathrm{ml})}$

\section{Statistical analysis}

The results were expressed as means \pm standard error of the mean (SEM). Significant differences between the groups were determined using $t$-test, and the differences between days within groups by using Repeated Measures Anova (GraphPad Prism 5.0 for Windows, GraphPad Software, San Diego, CA, USA).

\section{RESULTS}

\section{Health conditions}

Fortification of feed with probiotic cheeses and flaxseed positively affected overall health state of weaned pigs from the problematic herd (body temperature, consistency and water content of excrements) and reduced the prevalence of post-weaning diarrhoea by $29.2 \%$. The faecal score of these weaners was significantly lower and their body weight higher already after 14 days of feed supplementation.

\section{Intestinal metabolism}

The synergistic effect of additives on caecal microbial activity of weaners was reflected in: a significant increase in lactic acid bacteria (LAB) and bifidobacteria, increased production of volatile fatty acids (VFA) (acetic, propionic and butyric acids) and concurrently decreased counts of coliform bacteria and haemolytic E. coli. Supplementation of additives to weaners positively affected the population of $\mathrm{LAB}$ in the jejunum and supported the production of lactic acid (unpublished data).

\section{PUFAs metabolism}

The levels of $\omega-3$ PUFAs in the muscle of piglets are summarized in the Fig. 2. High levels of $\omega-3$ PUFA ALA in the diet significantly affected the level of this acid in muscles of experimental animals. In the group of animals fed rations fortified with lactobacilli and flaxseed an increase in ALA on days 7 and 14 post-weaning (both $\mathrm{P}<0.001$ ) was recorded in comparison with control pigs fed unfortified feed. Synthesis of EPA and DHA in the body of animals copied the levels of essential ALA. In the fortified group, we recorded a significant increase in the level of EPA on days 7 and 14 post-weaning $(\mathrm{P}<0.001)$. In comparison with the control group, the animals fed supplemented rations exhibited significantly increased biosynthesis of EPA on days 7 $(\mathrm{P}<0.01)$ and $14(\mathrm{P}<0.001)$ post-weaning. Conversion of EPA to DHA in the fortified group showed a similar increasing tendency and DHA levels were significantly higher after 14 post-weaning days and also in comparison with the control animals $(\mathrm{P}<0.001)$. Fortification of feed resulted in an increased synthesis of EPA $(\mathrm{P}<0.001)$ and subsequently increased conversion of EPA to DHA $(\mathrm{P}<0.001)$ compared to day 0 and the control group.

The levels of $\omega-6$ linolenic acid (LA) were less affected by the diet (see Table). In the fortified group they were significantly increased on day 14 compared to day $0(\mathrm{P}<0.01)$ and also in comparison with the control $(\mathrm{P}<0.001)$. At the same time, supplementation of the diet suppressed the conversion of LA to arachidonic acid (AA) on days 7 and 14 $(\mathrm{P}<0.05)$ and in comparison with the control $(\mathrm{P}<0.001)$. The increased intake of $\omega-3$ ALA in the experimental diet in the LFA group enhanced the activity of $\Delta$-6-desaturase in favour of $\omega$-3 EPA and DHA synthesis on days 7 and 14 in comparison to day $0(\mathrm{P}<0.001)$ and on days $7(\mathrm{P}<0.01)$ and $14(\mathrm{P}<0.001)$ in comparison to the control.

The levels of $\omega-6$ fatty acids in the m. biceps femoris of piglets after feeding supplemented (LFA) and non-supplemented (C) diet for 14 days after weaning are presented in Table1. 


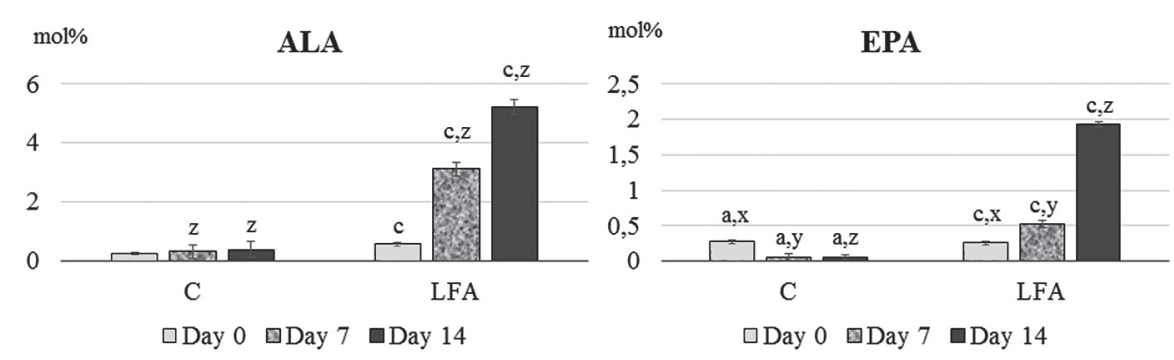

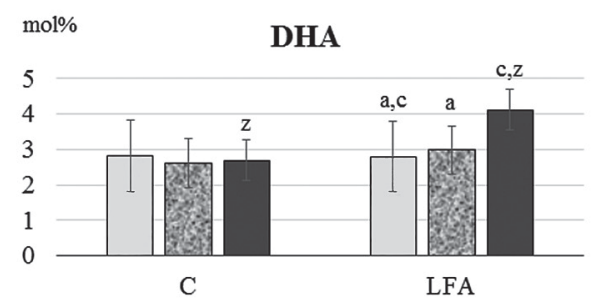

口Day 0 QDay 7 Day 14

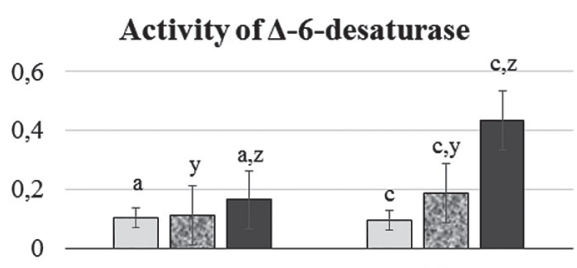

$\mathrm{C}$

LFA

$\square$ Day $0 \quad$ QDay 7 Day 14

Fig. 2. Effects of feeding PUFAs and flaxseed to weaned piglets (LFA) at 14 days post-weaning on the metabolism of $\omega$-3 PUFAs and activity of $\Delta$-6-desaturase in the $\mathrm{m}$. biceps femoris of piglets in comparison with the control group (C)

ALA - alpha-linolenic acid; EPA - eicosapentaenic acid; DHA - docosahexaenoic acid; Activity of $\Delta$-6-desaturase is the ratio of eicosapentaenic to arachidonic acid. Data are the means ( $m o l \%) \pm$ SEM (Repeated measures ANOVA). ${ }^{a, b}, c, x, y, z$ - Mean values with same superscript letters differ significantly $\left(a, x-P<0.05 ;{ }^{b, y}-P<0.01 ;^{c, z}-P<0.001\right)$. Superscript letters ${ }^{a, b, c}$ - show differences on days 7 and 14 post-weaning compared to day $0 ;{ }^{x, y, z}-$ show differences between the groups.

Table 1. The concentration of $\omega-6$ FAs in the $m$. biceps femoris of piglets after feeding supplemented (LFA) and non-supplemented (C) rations for 14 days after weaning

\begin{tabular}{|c|c|c|c|c|c|c|}
\hline \multirow{2}{*}{$\begin{array}{c}\text { Fatty acid } \\
\text { [mol \%] }\end{array}$} & \multicolumn{3}{|c|}{$C$} & \multicolumn{3}{|c|}{ LFA } \\
\hline & Day 0 & Day 7 & Day 14 & Day 0 & Day 7 & Day 14 \\
\hline LA & $19.27 \pm 1.02^{x}$ & $19.98 \pm 1.06$ & $21.3 \pm 2.06^{z}$ & $20.99 \pm 3.1^{\mathrm{b}, \mathrm{x}}$ & $23.54 \pm 2.44^{\mathrm{a}}$ & $27.86 \pm 1.99^{a, b, z}$ \\
\hline GLA & $0.33 \pm 0.01^{y}$ & $0.39 \pm 0.09$ & $0.27 \pm 0.01^{y}$ & $0.41 \pm 0.03^{y}$ & $0.39 \pm 0.05$ & $0.21 \pm 0.02^{y}$ \\
\hline DGLA & $0.28 \pm 0.01^{b, z}$ & $0.21 \pm 0.03^{b, z}$ & $0.22 \pm 0.04$ & $0.39 \pm 0.02^{z}$ & $0.34 \pm 0.03^{z}$ & $0.2 \pm 0.01$ \\
\hline AA & $11.01 \pm 1.1^{\mathrm{a}, \mathrm{z}}$ & $10.83 \pm 2.21^{\mathrm{a}, \mathrm{z}}$ & $9.28 \pm 0.98^{\mathrm{a}, \mathrm{z}}$ & $4.8 \pm 1.1^{\mathrm{a}, \mathrm{z}}$ & $5.1 \pm 0.95^{\mathrm{a}, \mathrm{z}}$ & $4.61 \pm 0.89^{\mathrm{a}, z}$ \\
\hline
\end{tabular}

LA — linoleic acid; GLA — gamma-linolenic acid; DGLA — dihommo-gamma-linolenic acid; AA — arachidonic acid; data are means (mol \%) \pm SEM (Repeated measures ANOVA). ${ }^{a, b}, x, y, z-$ Mean values in rows with same superscript letters differ significantly ${ }^{a, x}-P<0.05 ;{ }^{b, y}-P<0.01$;

$\left.{ }^{z}-\mathrm{P}<0.001\right)$. Superscript letters ${ }^{a, b}$ — show differences on days 7 and 14 compared to day $0 ; x, y, z$ - show differences between the groups. 


\section{DISCUSSION}

Fortification of feed with synbiotics (L. plantarum, L. fermentum and flaxseed) improved: the overall health of weaned piglets from a problematic herd, consistency and water content of excrements and increased their weight gains, similar to the results obtained in weaners infected with enterotoxigenic E. coli (ETEC) and fed diet fortified with probiotic strain of Bacillus amyloliquefaciens [14] and in gnotobiotic (germ-free) piglets supplemented with synbiotics (L. Plantarum and flax oil) [25]. Stimulation of the $\mathrm{LAB}$ population in the jejunum and ileum and increased concentration of lactic acid (final fermentation product of these bacteria) can positively affect the intestinal microenvironment of weanlings, particularly in terms of its antimicrobial effects [3]. Volatile fatty acids play an important role in the protection against intestinal infections; they prevent the development and absorption of toxic products of metabolism, participate in preservation of mucosal integrity and support growth of intestinal epithelial cells [39].

High level of essential $\omega$-3 PUFA ALA after 17 days of supplementation significantly increased ALA levels in skeletal muscles. On the basis of increased amount of substrate, conversion of ALA to long-chain $\omega-3$ PUFAs increased in the body and resulted in their increased concentration in muscle tissue. Our results agree with those obtained in studies conducted in pigs $[2,11,13,29]$, chickens [41] and sheep [36]. Similar to our study, increased proportions of $\omega$-3 PUFAs were observed in skeletal muscles and adipose tissue, but also in the tissues of heart, liver and brain after increased intake of ALA by feed [13, 26, 32]. However, they recorded an increased levels of ALA, eventually also EPA and docosapentaenoic acid (DPA), but the content of DHA (the acid important for the organism) was comparable with the control. A significant increase in DHA after the application of fish oil and fish meal was observed by other authors $[13,17]$. This increase in DHA was caused by a direct incorporation of DHA present in fish additives into tissues and not by the synthesis of DHA in the body which negatively affected organoleptic properties of products of animal origin. For this reason, $\mathrm{Ha}$ a $\mathrm{k}$ et al. [13] presented an opinion that the synthesis of DHA in the body is most likely not affected by the intake of its precursor in the diet, but is regulated strictly metabolically where desaturation and elongation of $\omega-3$ PUFA is blocked at the level of DPA synthesis. On the other hand, in agreement with our results, Perin i et al. [26] applied flax diet to mice and observed the highest level of ALA in the liver and consequently a significantly increased conversion of $\omega-3$ ALA to EPA and DHA with the highest levels on day 56 of application, accompanied by a significant decrease in the conversion of $\omega-6$ LA to AA and almost a 3-fold decrease in the $\omega-6: \omega-3$ PUFA ratio. Similarly Kaštel' et al. $[15,16]$ conducted a study with supplementation of flaxseed and lactobacilli to gnotobiotic pigs and piglets, the optimum model for digestive physiology and lipid metabolism, and observed significantly increased levels of $\omega-3$ PUFAs EPA and DHA and decreased level of $\omega-6$ AA in the blood serum of these animals. Omega-6 AA is the major precursor of eicosanoids at cleavage of phospholipids by means of phospholipase A2 which serves as a substrate for enzymes of cyclooxygenase (COX) and lipoxygenase (LOX) pathways resulting in the production of pro-inflammatory cytokines. On the contrary, $\omega-3$ PUFAs produce eicosanoids with anti-inflammatory properties [27]. The mechanisms by which $\omega$-3 PUFAs induce their immunosuppressive effect is the inhibition of AA metabolism, therefore the production of pro-inflammatory eicosanoids, inflammatory cytokines, and concentration of lipids and lipoproteins in the blood [42], and significant decrease in the activity of genes is responsible for inflammatory reaction [38].

After continuous fortification of feed with synbiotics in our study, we observed decreased conversions of LA to GLA (gama-linolenic acid) and AA, despite significantly increased level of LA. The results of our study confirmed that after increased absorption of the $\omega$-3 PUFA-fortified feed received by animals, they showed: predominant conversion of $\omega-3$ PUFA ALA to EPA and DHA, increased activity of $\Delta$-6-desaturase in favour of $\omega$-3 PUFAs synthesis and reduced synthesis of $\omega-6$ PUFAs GLA and AA. Mammals lack the enzymes for the synthesis of highly non-saturated fatty acids such as AA and DHA from acetyl-CoA, and synthesises them from precursors, essential PUFAs [22], with the amount of substrate available to the common enzyme $\Delta-6$ desaturase which plays the key role. An increased absorption of ALA ( $\omega-3)$ is therefore the cause of the predominant biosynthesis of EPA to DHA at the expense of AA $(\omega-6)$ synthesis $[12,26]$. After supplementation of a diet with flaxseed, a 2.4-fold increase in DHA was observed by Sh a pir a et al. [28] in hens. Significantly higher concentrations of all $\omega-3$ PUFAs, including DHA, and a subsequent decrease in $\omega-6: \omega-3$ PUFA ratio was recorded by Kouba 
et al. [17] in rabbits and by Enser et al. [7] in sows and boars. Our results agree with those of these authors and confirm the claims of other authors $[10,12]$. The increased absorption of essential ALA in the body stimulates more intensive conversion of ALA to EPA and DHA, which can be used in practice by the food industry already after shortterm (21-28 days) application of flaxseed [17]. The results obtained in one research paper proved that nutritional shortcomings during prenatal development of the foetus result in permanent changes in the physiology of progeny, including the metabolism of lipids and increased the risk of chronic diseases in adults [30]. Recent studies indicate that the relevant mechanisms are modulated also by DHA, the main $\omega-3$ FA with potential impact on growth and development of children [20], and by general changes in the content of $\omega-3$ FAs in the nutrition of the mother which subsequently affects the metabolism of lipids in the foetus [1]. Supplementation of animal feed with flaxseed or flax oil is a suitable way of satisfying the requirements of consumers of animal products by nutritionally beneficial components. However, the absence of the effect of feed fortified with flaxseed on the level of DHA in pig tissues has not yet been fully explained. It could be caused by a low ability of the pig to synthesise DHA from EPA or by rapid utilization of DHA in the tissues of these animals. These assumptions should be subjected to further investigation. The ability to increase the level of DHA in pork would bring considerable nutritional benefits. The relevant research should focus on defining the optimum amount and period of $\omega-3$ PUFAs supplementation, in order to decrease the risk of increased lipid oxidation and the related adverse effects on quality of animal products [18].

\section{ACKNOWLEDGEMENTS}

This study was supported by the Research Agency of the Ministry of Education, Science, Research and Sport of the Slovak Republic (VEGA grant No. 1/0476/16) and the project IGA 15/2016.

The authors would like to express their special thanks to Mrs. M. Kozačková and Mgr. J. Kalatová for their technical assistance.

\section{REFERENCES}

1. Amrita, A. K., Anvita, A. K., Sadhana, R. J., 2015: Maternal omega-3 fatty acids and micronutrients modulate fetal lipid metabolism. Prostag. Leukotr. Ess., 98, 49-55.

2. Bečková, R., Václavková, E., 2010: The effect of linseed diet on carcass value traits and fatty acid composition in muscle and fat tissue of fattening pigs. Czech J. Anim. Sci., 55, 313-320.

3. Belenguer, A., Duncan, S. F., Calder, A. G., Holtrop, G., Louis, P., Lobley, G.E., Flint, H. J., 2006: Two routes of metabolic cross-feeding between Bifidobacterium adolescentis and butyrate producing anaerobes from the human gut. Appl. Environ. Microb., 72, 3593-3599.

4. Bomba, A., Jonecová, Z., Koščová, J., Nemcová, R., Gancarčíková, S., Mudroňová, D. et al., 2006: The improvement of probiotics efficacy by synergistically acting components of natural origin. Biologia, Bratislava, 61, 729-734.

5. Borovská, D., Nemcová, R., Gancarčíková, S., Koščová, J., 2013: The synbiotic effect of lactobacilli and flaxseed on selected intestinal microflora and organic acid levels in weaned piglets. Microbiology, 2, 82-86.

6. Carlson, L.A., Hoegsted, B., Oroe, L., 1963: Effect of atromid on plasma lipids and lipoproteins in subjects with hyperlipoproteinemia (a preliminary report). J. Atherocer. Res., 3, 467-474.

7. Enser, M., Richardson, R.I., Wood, J.D., Gill, B.P., Sheard, P. R., 2000: Feeding linseed to increase the n-3 PUFA of pork: fatty acid composition of muscle, adipose tissue, liver and sausages. Meat Sci., 55, 201-212.

8. Folch, J., Lees, M., Sloane Stanley, G. H., 1957: A simple method for the isolation and purification of total lipids from animal tissues. J. Biol. Chem., 226, 497-509.

9. Gomes, B.C., Rodriguez, M.R., Winkelströter, L.K., Nomizo, A., De Martinis, E. C., 2012: In vitro evaluation of the probiotic potential of bacteriocin producer Lactobacillus sakei. J. Food Protect, 75, 1083-1089.

10. Grofová, Z., 2010: Fatty acids (In Czech). Medicina pro praxi (Medicine for Practice), 7, 388-390.

11. Guillevic, M., Kouba, M., Mourot, J., 2009: Effect of a linseed diet or a sunflower diet on performances, fatty acid composition, lipogenic enzyme activities and stearoyl-CoA-desaturase activity in the pig. Livestock Science, 124, 288-294.

12. Gunstone, F.D., 2012: Fatty Acids and Lipid Chemistry. Springer London, $268 \mathrm{pp}$.

13. Haak, L., De Smeet, A., Fremaut, D., Van Walleghem, K., Raes, K., 2008: Fatty acid profile and oxidative stability of pork in- 
fluence by duration and time of dietary linseed or fish oil supplementation. J. Anim. Sci., 86, 1418-1425.

14. Ji, J., Hu, S. L., Ciu, Z. W., Li, W. F., 2013: Probiotic Bacillus amyloliquefaciens mediate M1 macrophage polarization in mouse bone marrow-derived macrophages. Archives of Microbiology, 195, 349-356.

15. Kaštel', R., Tučková, M., Vaško, L., Pistl, J., Revajová, V., Eliáš, D. et al., 2003: The effect of oil with elevated content of n-3 polyunsaturated fatty acids (PUFA) on some metabolic and immunological parameters in germ-free and conventional piglets. Czech J. Anim. Sci., 48, 233-23.

16. Kaštel, R., Bomba, A., Vaško, L., Trebunová, A., Mach, P., 2007: The effect of probiotics potentiated with polyunsaturated fatty acid on the digestive tract of germ-free piglets. Vet. Med. Czech, 52, 63-68.

17. Kouba, M., Benatmane, F., Blochet, J.E., Mourot, J., 2008: Effect of a linseed diet on lipid oxidation fatty acid composition of muscle, perirenal fat and raw and cooked rabbit meat. Meat Sci., 80, 829-834.

18. Kouba, M., Mourot, J., 2011: A review of nutritional effects on fat composition of animal products with special emphasis on n-3 polyunsaturated fatty acids. Biochemie, 93, 13-17.

19. Kubašová, I., Mudroňová, D., 2014: The influence of probiotic Lactobacilli and flaxseed on the immune response of weaned piglets experimentally infected with enterotoxigenic E. coli. Folia Veterinaria, 58, 122-126.

20. Lee, H.S, Villarreal, A. B., Biessy, B., Duarte-Salles, T., Sly, P.D., Ramakrishnan, U. et al., 2014: Dietary supplementation with polyunsaturated fatty acid during pregnancy modulates DNA methylation at IGF2/H19 imprinted genes and growth of infants. Physiol. Genomics, 46, 851-857.

21. Li, Q., Brendemuhl, J.H., Jeong, K. C., Badinga, L., 2014: Effects of dietary omega-polyunsaturated fatty acids on growth and immune response of weaning pigs. J. Anim. Sci., 56, 1-7.

22. Nakamura, M.T. Cheon, Y., Li, Y., Nara, T.Y., 2004: Mechanisms of regulation of gene expression by fatty acids. Lipids, 39, 1077-1083.

23. Nemcová, R., Lauková, A., Gancarčíková, S., Kaštel, R., 1997: In vitro studies of porcine lactobacilli for possible probiotic use. Berl. Munch. Tierarztl., 110, 413-417.

24. Nemcová, R., Guba, P., Gancarčíková, S., Bomba, A., Lauková, A., 2003: Study of probiotic properties of lactobacilli in poultry (In Slovak). Agriculture, 49, 75-80.

25. Nemcová, R., Borovská, D., Koščová, J., Gancarčíková, S., Mudroňová, D., Buleca, V., Pistl, J., 2012: The effect of supplementation of flax-seed oil on interaction of Lactobacillus plan- tarum - Biocenol ${ }^{\text {Tst }}$ LP96 and Escherichia coli O8:K88ab:H9 in the gut of germ-free piglets. Res. Vet. Sci., 93, 39-41.

26. Perini, J. A. L., Stevanato, F. B., Visentainer, J. E. L., Sargi, S. C., Oliveira, M. M., Souza, N.E. et al., 2011: Incorporation of $\mathrm{n}-3$ fatty acids by the liver of mice fed linseed oil as a function of feeding duration. Braz. Arch. Biol. Techn., 54, 307-313.

27. Serhan, C.N., Chiang, N., Van Dyke, T.E., 2008: Resolving inflammation: dual anti-inflammatory and pro-resolution lipid mediators. Nat. Rev. Immunol., 8, 349-361.

28. Shapira, N., Weil, P., Loewenbach, R., 2008: Egg fortification with $n-3$ polyunsaturated fatty acids (PUFA): nutritional benefits versus high n-6 PUFA western diets and consumer acceptance. Isr. Med. Assoc. J., 10, 262-265.

29. Shin, S. S., Dixon, C. E., 2011: Oral fish oil restores striatal dopamine release after traumatic brain injury. Neurosci. Lett., $496,168-171$.

30. Schindler, M., Pendzialek, M., Navarrette Santos, A., Plösch, T., Seyring, S., Gürke, J. et al., 2014: Maternal diabetes leads to unphysiological high lipid accumulation in rabbit preimplantation embryos. Endocrinology, 155, 1498-1509.

31. Sopková, D., Hertelyová, Z., Andrejčáková, Z., Vlčková, R., Gancarčíková, S., Petrilla, V. et al., 2017: The application of probiotics and flaxseed promotes metabolism of n-3 polyunsaturated fatty acids in pigs. J. Appl. Anim. Res., 45, 93-98.

32. Tang, X., Li, Z. J., Xu, J., Xue, Y., Li, J.Z., Wang, J.F. et al., 2012: Short term effects of different omega-3 fatty acid formulation on lipid metabolism in mice fed high or low fat diet. Lipids in Health and Disease, 11, 70. http://dx.doi.org/10.1186/1476511X-11-70.

33. Tanghe, S., Missotten, J., Raes, K., Vangeyte, J., De Smet, S., 2014: Diverse effects of linseed oil and fish oil in diets for sows on reproductive performance and pre-weaning growth of piglets. Livest. Prod. Sci., 164, 109-118.

34. Tvrzická, E., Vecka, M., Staňková, B., Žák, A., 2002: Analysis of fatty acids in plasma lipoproteins by gas chromatography-flame ionization detection: quantitative aspects. Anal. Chim. Acta, 465, 337-350.

35. Vaisey-Genser, M., Morris, D.H., 2003: Introduction, history of the cultivation and uses of flaxseed. In Muir, A.D., Westcott, N.D. (Eds.): Flax, the Genus Linum. Taylor and Francis, London, $1-21$.

36. Wachira, A. M., Sinclair, L. A., Wilkinson, R. G., Ener, M., Wood, J.D., Fisher, A. V., 2002: Effects of dietary fat source and breed on the carcass composition, n-3 polyunsaturated fatty acid and conjugated linoleic acid content of sheep meat and adipose tissue. Br. J. Nutr., 88, 697-709. 
37. Wang, D. F., Zhou, L. L., Zhou, H. L., Hou, G. Y., Zhou, X., Li, W., 2016: Effects of piper sarmentosum extract on the growth performance, antioxidant capability and immune response in weaned piglets. J. Anim. Physiol. Anim. Nutr., April 4, 1-8.

38. Weaver, K. L., Ivester, P., Seeds, M., Case, L. D., Arm, J. P., Chilton, F. H., 2009: Effect of dietary fatty acids on inflammatory gene expression in healthy humans. J. Biol. Chem., 284, 5400-15407.

39. Wong, J.M., Jenkins, D. J., 2007: Carbohydrate digestibility and metabolic effects. J. Nutr., 137, 2539-2546.

40. Woods, V. B., Fearon, A. M., 2009: Dietary sources of unsaturated fatty acids for animals and their transfer into meat, milk and eggs. Livest. Prod. Sci., 126, 1-20.
41. Zelenka, J., Jarošová, A., Schneiderová, D., 2008: Influence of n-3 and n-6 polyunsaturated fatty acids on sensory characteristics of chicken meat. Czech. J. Sci., 53, 299-305.

42. Zhao, Y., Jonshi-Barve, S., Barve, S., Chen, L. H., 2004:

Eicosapentaenoic acid prevents LPS-induced TNF-alpha expression by preventing NF-kappaB activation. J. Am. Coll. Nutr., 23, $71-78$.

Received September 21, 2016

Accepted November 11, 2016 